\section{The pheasant's revenge: an unusual zoonotic injury}

Hunting accidents are many and varied. We report an unusual injury sustained during a pheasant shoot.

\section{Case report}

A woman was admitted on Boxing Day morning complaining of abdominal pain. Nine days previously she had been on a hunting party where her husband had been demonstrating his ballistic prowess. She was sitting on his shooting stick a few paces behind the gun line and watched him bagging a low, fastflying pheasant. The bird, however, continued on its normal trajectory and came down low and fast. She saw her husband duck and succeeded in turning side on but was struck on the lower lateral aspect of her left chest wall by the lifeless bird, which weighed $2.04 \mathrm{~kg}$. She was examined at the local casualty department and was discharged without further investigation. Subsequently, she experienced pain over the site of the injury and noticed progressive abdominal discomfort and distension. She became anorectic and unwell with worsening of her pain on the day of admission.

On examination she was pale but not shocked. There was pronounced tenderness over the 9th, 10th, and 1lth ribs on the left, with signs of underlying pulmonary collapse. Abdominal examination showed that she had a soft, distended abdomen with considerable tenderness on the left. The bowel sounds were active, and rectal examination yielded normal results. Her haemoglobin concentration was $92 \mathrm{~g} / \mathrm{l}$, and abdominal radiography showed a large soft tissue mass in the left hypochondrium with displacement of the splenic flexure towards the midline. After resuscitation laparotomy showed a discrete capsular tear over the diaphragmatic surface of the spleen with evidence of a ruptured subcapsular haematoma; $1100 \mathrm{ml}$ of liquid and clotted blood was removed and a splenectomy was performed. Her recovery was uneventful.

\section{Comment}

Animal bites and their management are well documented, ${ }^{12}$ and there are also anecdotal reports of big game, such as lions, tigers, rhinoceroses, etc, crushing their tormentors, but there seem to be no reports of pheasants inflicting injuries as in our patient. It is perhaps understandable that our patient could not see the irony of the fact that a dead fowl delivered a near fatal injury. We can only hope that when served the bird made up for its earlier misdemeanour.

We thank Mr R H S Lane for allowing us to report this case.

1 Edlich RF, Spengler MD, Rodeheaver GT. Mammalian bites. Compr Ther 1983;9:41-7.

2 Rest JG, Goldstein EJ. Management of human and animal bite wounds. Emerg Med Clin Nori Am 1985;3:117-26.

\section{Royal Hampshire County Hospital, Winchester}

M C P WILKINSON, BSC, FRCS, senior surgical house officer G KLEIN, BM, house surgeon

MARK CORNELL, medical student, Southampton Medical School R M RAINSBURY, MS, FRCS, senior registrar in surgery

Correspondence to: Mr M C P Wilkinson, Department of Plastic Surgery, Queen Mary's Hospital, Roehampton, London SW 15.

\section{Possible pituitary dwarfism from the Roman period}

In modern publications dwarfism is uncommon. Nevertheless, in ancient populations there are even fewer reports of the condition, most of the descriptions being of achondroplasia. Here I report a case of possible pituitary dwarfism encountered in a routine analysis of specimens from the Roman period.

\section{Description}

Examination of the burials from a Roman cemetery site in Gloucester showed a skeleton (No 557) of abnormally small proportions (figure). Pelvic morphology suggests that the remains are those of a woman. The distal epiphyses of the right humerus and the proximal epiphysis of the right radius and ulna have only just fused. The parts of the right innominate bone have fused but the iliac crest is unfused. The portion of the sacrum which survives shows non-fusion of the

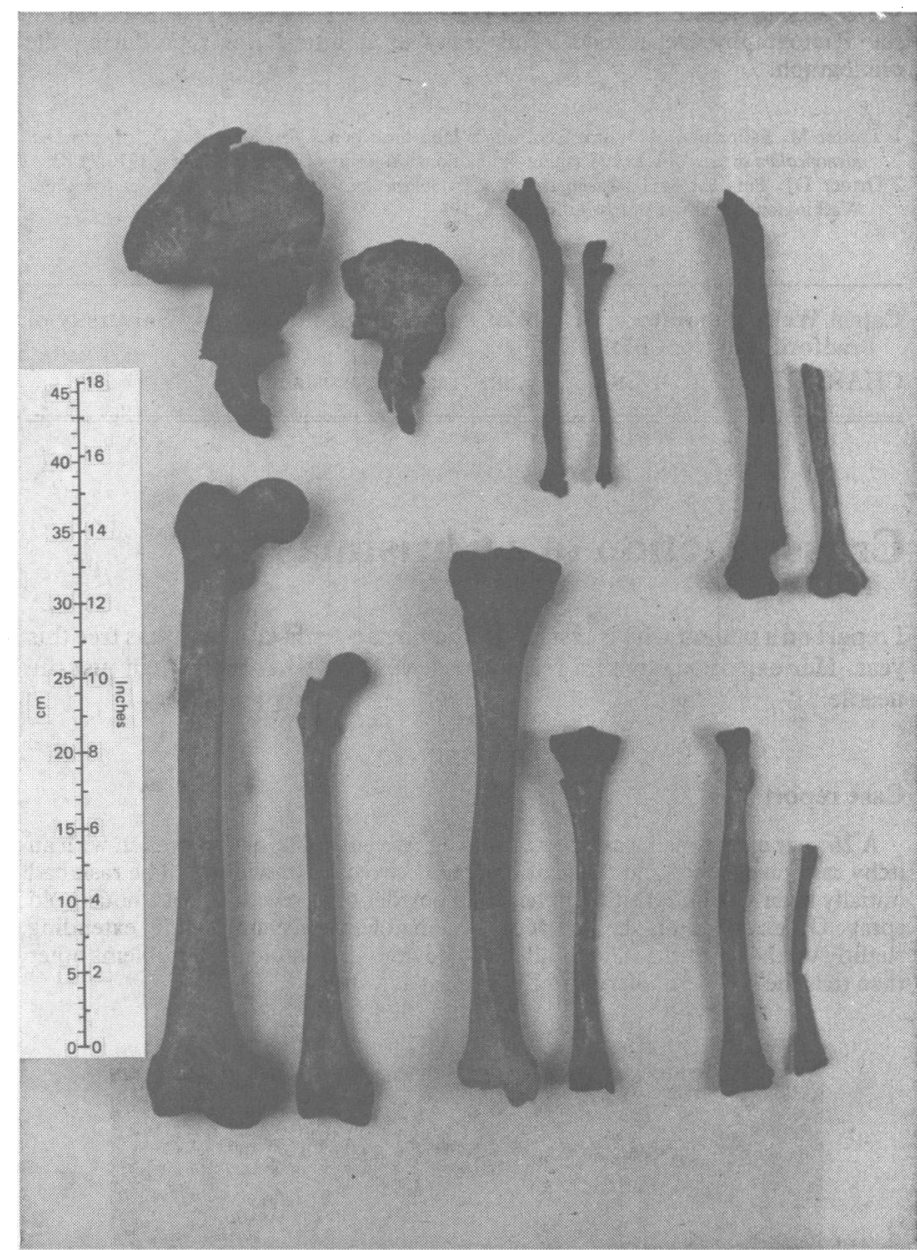

Skeletal remains from skeleton No 557 with normal female bones from the same cemetery for comparison.

epiphyseal lamina for the right sacroiliac joint. The right femoral condyles and head have fused to the diaphysis but the epiphyseal line of the latter is still visible. The epiphyses of the right tibia have fused but the proximal epiphyseal line is still present. Measurements of the parietal chord and arc of the skull give lower values than those for the remaining women from the cemetery. Epiphyseal union suggests that this skeleton belonged to a woman who was about 21-22 years old at death, though evidence from tooth development conflicts with this estimate: the third mandibular molar is not present and the mandibular canines are only just erupting. The cranial sutures have recently closed.

The bones are all gracile, slender, and shorter than normal but in proportion with each other. Muscle development was poor. Estimation of stature by using the maximum length of the right femur ${ }^{1}$ was $131.2 \mathrm{~cm}$. The mean stature for the women in the cemetery was $153 \mathrm{~cm}$. There were no appreciable pathological changes on any of the bones except areas of periosteal new bone formation on the outer surfaces of the ilium and on the anterior distal and the medial proximal shaft of the right femur, and large plaques of extracortical new bone over the whole of both the endocranial and extracranial surfaces of the frontal bone. The extracranial new bone appears less organised and therefore possibly younger than the endocranial deposits. This diffuse homogeneous deposition suggests a possible postinfective cause. $x$ Ray films of the long bones show persistent epiphyseal lines, and Harris lines of arrested growth in the distal shaft of the femur are evident.

\section{Comment}

The findings in this skeleton suggest proportionate dwarfism, which has several possible causes, among which pituitary dwarfism is the most likely. Given the presence of plaques of periosteal new bone on the endocranial surface of the skull and on some of the postcranial bones, the aetiology is likely to be postinfective, possibly tuberculous, but clearly this must remain speculative. Only one definite paleopathological case of pituitary dwarfism has been reported, in a skeleton from New Mexico, ${ }^{2}$ and this showed features comparable with those in this specimen from Gloucester.

I thank Dr D J Ortner of the Department of Anthropology, Smithsonian Institution, Washington DC, USA, and Dr Keith Manchester of the Calvin Wells Laboratory, University of Bradford, for their useful comments; the excavators (P J Cracknell, A V C Vincent, C R Wallace, and V Yuill) for allowing me to use 
the specimen before publication of the cemetery report; and Jean Brown of the Photography Department, University of Bradford, for reproducing the photograph.

1 Trotter M. Estimation of stature from intact long limb bones. In: Stewart TD, ed. Personal identification in mass disasters. Washington: National Museum of Natural History, 1970:71-83. 2 Ortner DJ, Putschar WGJ. Identification of pathological conditions in human skeletal remains.

Washington: Smithsonian Institution Press, 1981.

Calvin Wells Laboratory, School of Archaeological Sciences, University of Bradford, Bradford BD7 1DP

CHARLOTTE A ROBERTS, .MA, SRN, research assistant

\section{Cross reaction to a Christmas tree}

I report on a patient who is resigned to having an artificial Christmas tree this year. Her experience with a real one last year gave her more than just the needle.

\section{Case report}

A 26 year old woman was referred during Advent 1986, having woken with an itchy rash on the face and dorsa of the hands two days previously. The rash had initially been attributed either to her soap powder or to recent use of a household spray. On examination she had acute eczema of the face and hands, extending slightly up the forearms. She recalled no previous dermatological problems other than that she had been allergic to Elastoplast as a child.

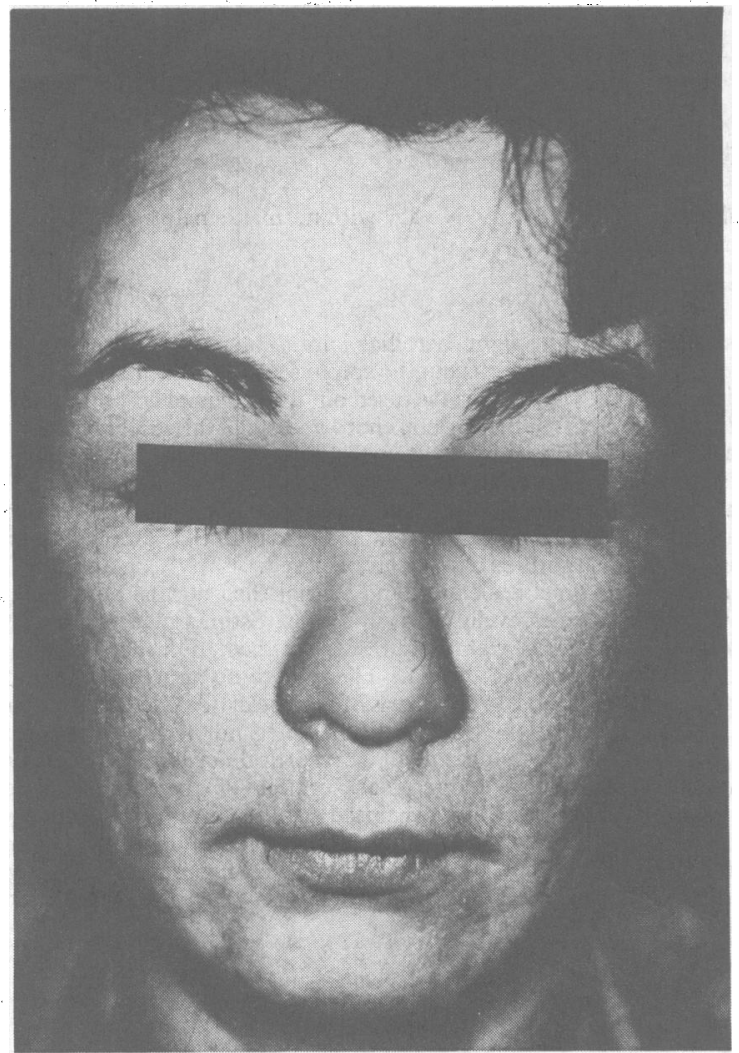

Facial appearance at presentation.

Further inquiry disclosed that four days previously she and her husband had selected a Christmas tree. She remarked that the chosen specimen was the strongest smelling Christmas tree that she had ever come across, and on the journey home she was in close proximity to it in the back of their Ford Fiesta. While decorating the tree that night she came into contact not only with the bark, branches, and needles but also with resin that was exuding freely from the trunk. Her rash appeared about 36 hours later.

She was treated with a course of prednisolone (reducing from $30 \mathrm{mg}$ daily to zero over six days) and $1 \%$ hydrocortisone cream, and her eczema had resolved completely when she was seen one week later.

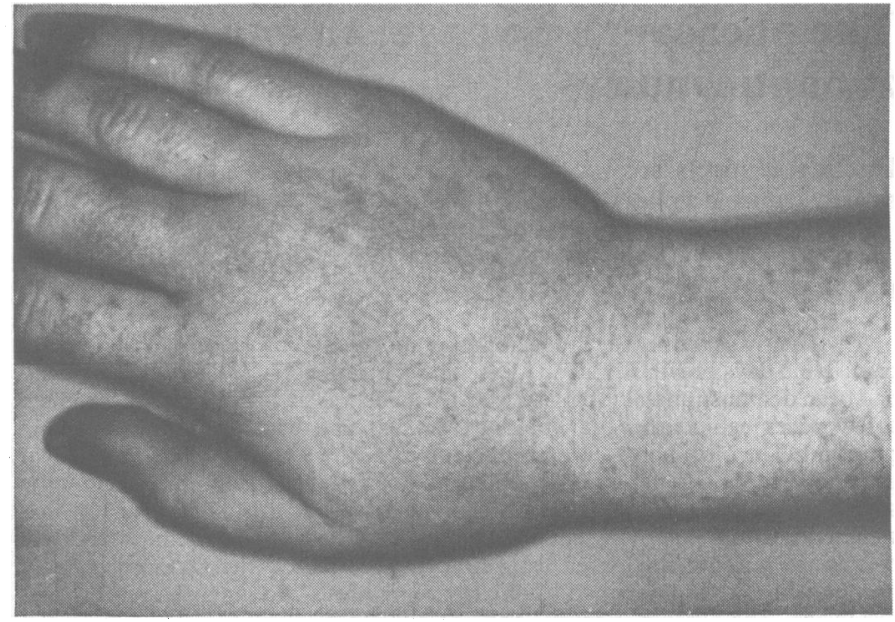

Appearance of hand at presentation.

A diagnosis of allergy to Christmas trees was suggested, and she was patch tested with a battery of allergens, including the standard battery of the International Contact Dermatitis Research Group, her household spray, and bark and needles from the offending Christmas tree. The diagnosis was confirmed by strongly positive reactions to colophony (rosin), bark, and needles at 48 hours. (The bark or needles were not expected to provoke an irritant reaction, and no control tests were performed.) The botanical identity of the tree remained a mystery because it had been disposed of quite promptly.

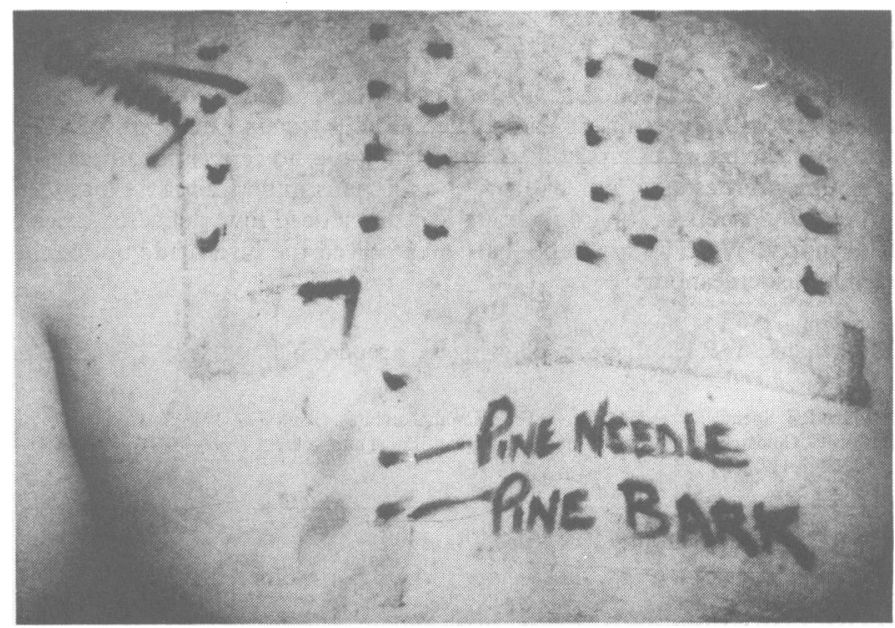

Positive reactions to patch tests of colophony, pine needles, and bark.

\section{Comment}

The family Pinaceae consists of 250 species in ten genera and includes pine, fir, and spruce. ${ }^{1}$ Occupational contact dermatitis caused by these trees is a recognised problem in, for example, woodcutters, forest workers, carpenters, and florists, who may become sensitised by contact with the wood, sawdust, or lichens living on the bark. The main sensitising substances are terpenes such as $\alpha$-pinene, $\delta$-3-carene, and abietic acid (from abies (Latin), meaning a fir. $)^{1}$

Several constituents of everyday products derived from Pinaceae trees also have the potential to produce contact dermatitis. These include Canada balsam (derived from the fir Abies balsamea), turpentine (obtained from several different species, depending on geographical locality), and colophony. ${ }^{1}$ Colophony (rosin) is derived mainly from Pinus palustris and, though it probably consists of several hundred substances, its main constituents are abietic acid and its isomers or derivatives.

Domestically, colophony is present in varnishes and furniture polish. The commonest cause of allergy, however, is adhesive tape..$^{1-5}$ Though antioxidants and preservatives in the tape may cause contact allergy, positive reactions to patch tests are usually due to colophony or abietic acid derivatives, or both, which are present in the adhesive itself. ${ }^{2.5}$ Cross sensitivity between plasters and trees of the Pinaceae family is recognised by dermatologists (in, for example, two patients who were sensitised by plaster and cross reacted to their Cupressus leylandii hedges) ${ }^{45}$ but probably not by others. 